\title{
The Role of Lymph-vascular Space Invasion towards Disease of Free Survival and Overall Survival Cancer in High-Risk Endometrial Cancer Endometrioid Type Patients
}

Brahmana A skandar Tjokroprawiro ${ }^{1 *}$, Trianggono Bagus Ariyanto ${ }^{2}$, Indra Yuliati ${ }^{1}$, Willy Sandhika ${ }^{3}$

${ }^{1}$ Oncology Division, Department of Obstetrics and Gynecology, Faculty of Medicine-Dr. Soetomo Teaching Hospital, Universitas Airlangga, Surabaya 60131, Indonesia

${ }^{2}$ Department of Obstetrics and Gynecology, Faculty of Medicine-Dr. Soetomo Teaching Hospital, Universitas Airlangga, Surabaya 60131, Indonesia

${ }^{3}$ Departement of Clinical Pathology, Faculty of Medicine-Dr. Soetomo Teaching Hospital, Universitas Airlangga, Surabaya 60131, Indonesia

Article History:

\section{ABSTRACT}

Major prognostic factors of endometrial cancer include stage, age, histopathological type, grading, depth of invasion of myometrium, and presence of Lymph-vascular Space Invasion (LVSI). This study evaluated the LVSI in disease free survival (DFS) and overall survival $(\mathrm{OS})$ in high-risk endometrial cancer endometrioid type. This was a retrospective study. Survival analysis using Kaplan-Maier curve, log rank test, cox-regression and logistic regression were used to determine effects among variables. Among fifty-six patients, $43 \%$ of patients were $<60$ years, $73 \%$ with $\mathrm{BMI}<30,17 \%$ were multiparous, and $79 \%$ were menopausal patients. There were $32 \%$ of patients with positive LVSI. Most clinical stages were found in stage III with 31 cases (55\%). Patients with positive LVSI had OS lower than patients with negative LVSI (50\% vs $55.3 \%)$. There were no significant results of LVSI as prognostic factor for OS. Patients with LVSI positive had survival time of 26.5 months (20.5 - 32.5). There were no significant results of LVSI as prognostic factor for DFS.
Revised: 05.04.2020

Accepted: 11.05.2020

Patients with positive LVSI had lower DFS than patients with negative LVSI (81.8\% vs $85.7 \%)$. There were significant results of LVSI as prognostic factor for high-risk endometrioid type endometrial cancer with stage endometrial cancer with $p=0.01$. LVSI acts as prognostic factor for high-risk endometrioid type endometrial cancer associated with stage endometrial cancer. However, there was no effect in DFS and OS.

Keywords: Endometrial cancer, LVSI, disease free survival, overall survival

Correspondance

Brahmana Askandar Tjokroprawiro

Department of Obstetrics and Gynecology, Faculty of Medicine-Dr. Soetomo Teaching Hospital, Universitas Airlangga, Surabaya 60131, Indonesia

Email: brahmanaaskandar@gmail.com

DOI: $10.31838 /$ srp. 2020.5.26

@Advanced Scientific Research. All rights reserved

\section{INTRODUCTION}

Endometrial cancer is a case of gynecological malignancy in developed countries, and gynecological malignancies rank second after cervical cancer in developing countries. The endometrial carcinomas are classified as Typel endometrioid endometrial carcinomas (EECS) and Type II nonendometrioid endometrial carcinomas (NEECs) $(1,2)$.

In 2012 around the world a total of 527,600 women suffered from endometrial cancer (3). There were 346 endometrial cancer cases found between January 2011 and August 2016 in Dr. Cipto M angunkusumo Hospital, Jakarta, Indonesia (4). In addition, women who are diagnosed with epithelial ovarian cancer (EOC) can suffer endometrial premalignancies, and women with endometriosis haverisk to endometrial cancer, whereas the Natural Kill (NK) cell is lower $(5,6)$. Besides, vascular endothelial growth factor (VEGF) is angiogenic factor which plays important roles in the growth of endometrial cancers (7).

Total abdominal hysterectomy and bilateral salpingo oophorectomy (TAH-BSO) surgery is the first choice in endometrial cancer patients, especially in early stage endometrial cancer patients. This research was made because until now there are no data regarding the outcome of postoperative high-risk endometrioid cancer patients after surgery and given adjuvant therapy seen from Lymph Vascular Space Invasion (LVSI) as consideration for evaluation. Adjuvant therapy options in the form of chemotherapy or radiotherapy are adjusted according to clinical and pathological prognostic factors. Major prognostic factors of endometrial cancer include stage, age, histopathological type, grading, depth of invasion of myometrium and presence of LVSI $(8,9)$. Adjuvant therapy is said to improve survival rates of high risk type endometrial cancer patients and reduce loco-regional recurrence rates. However, there are affective psychopathological comorbidities affecting on the quality of life of patients who are undergoing radiotherapy (10).

LVSI is a process in which cancer cells invade the vascular system or lymphatic system. This process shows a prognostic factor because of the high incidence of recurrence and death. Found in $8-10 \%$ of patients with stage I (staging using FIGO (Federation of Gynecology and Obstetrics) criteria for endometrial cancer, this number will increase with the degree of grading of endometrial cancer, depth of invasion, and older age (11). This study evaluated the LVSI in disease free survival (DFS) and overall survival (OS) in high-risk endometrial cancer endometrioid type.

\section{METHODS}

This was an analytical retrospective study using medical record data and slides from anatomic pathology with samples of high risk endometrioid type cancer patients in Dr. Soetomo General Hospital, Surabaya. The inclusion criteria in this study were patients with high-risk endometrioid type of cancer, surgical staging, and receiving adjuvant therapy. Exclusion criteria in this study were high risk type II endometrial cancer patients (clear cell, serous carcinoma), data needed for incomplete analysis, missing medical records, and other malignancies in patients. 
The outcomes evaluated were OS and DFS. Prognostic factor variables evaluated included age, body mass index (BMI), parity, LVSI, stage, and recurrence. Survival analysis was done using the Kaplan-M eier curve. The log rank test was used for univariate analysis, while cox regression and logistic regression were used to determine the effect between variables.

\section{RESULTS}

From tracking data on operating room registration references and medical record references at Dr. Soetomo during the 2014-2016 period of endometrial cancer patients, 150 endometrial cancer patients had successfully recorded. Sorting according to inclusion criteria, the total number of patients who met the inclusion criteria was 56 patients.

The prognostic factors such as age, BMI, parity, menopausal status, LVSI, and staging of high-risk endometrioid type endometrial cancer patients are shown in Table 1. From the characteristics of our patients, $43 \%$ of patients aged $<60$ years, $73 \%$ with $\mathrm{BMI}<30,17 \%$ were multiparous, and $79 \%$ were menopausal patients. There were $32 \%$ of patients with positive LVSI. M ost clinical stages were found in stage III with 31 cases (55\%), followed by stage IB grade III with 13 cases $(23 \%)$, and stage II with 12 cases $(21 \%)$.

Analysis of OS was performed on each variable group (Table 2). In this study, 26 patients (39\%) died. OS variables in this study were age, BMI, parity, menopausal status, LVSI, staging, including high risk, and recurrence. Of all these variables, there was not a single statistically significant number of OS. From a total of 56 high-risk endometrioid type endometrial cancer patients, 18 patients (32\%) had LVSI. Nine patients (50\%) with LVSI positive results died, and 17 patients (45\%) with LVSI negative died. In positive LVSI cases the median survival time was 26.5 months (95\% $\mathrm{Cl} 20.5$ - 32.5), while patients with negative LVSI had a median survival time of 26.1 months ( $95 \%$ Cl 22.1 - 30.1).

Table 1: Characteristics of patients

\begin{tabular}{llll}
\hline Characteristics & n & $\%$ & Mean \\
\hline A ge (years) & & & \\
$<60$ & 24 & 43 & 55.1 \\
$\geq 60$ & 32 & 57 & \\
Body M ass Index $\left(\mathrm{kg} / \mathrm{m}^{2}\right)$ & & & \\
$<30$ & 41 & 73 & 26.5 \\
$>30$ & 15 & 27 & \\
Parity & & & \\
Nulliparous & 17 & 30 & \\
Multiparous & 39 & 70 & \\
M enopause & & & \\
Yes & 44 & 79 & \\
No & 12 & 21 & \\
LVSI & & & \\
Positive & 18 & 32 & \\
Negative & 38 & 68 & \\
Stadium & & & \\
IB grade III & 13 & 23 & \\
II & 11 & 21 & \\
III & 32 & 55 & \\
\hline
\end{tabular}

Table 3 shows DFS for 3 years. In this study, 32 patients (100\%) entered the DFS criteria, and 5 patients (19\%) had a recurrence. LVSI is a prognostic factor in endometrial cancer regarding recurrence. In this study, the overall rate of DFS in patients with LVSI positive was $81.8 \%$ while in patients with LVSI negative was $85 \%$. There was no significant effect between LVSI and DFS.

In this study, we want to prove the role of LVSI as a prognostic factor for high-risk endometrioid type endometrial cancer, divided by risk factor parameters in endometrial cancer as shown in Table 4. In this study based on the category of staging, it was found that the higher the stage, the higher the likelihood of obtaining LVSI in the anatomic pathology examination. T otal of 18 patients (32\%) with positive LVSI, 15 patients (48\%) were known to suffer from stage III. There were significant results only in LVSI with stage endometrial cancer with $p=0.01$.

Table 2: O verall survival during 3 years

\begin{tabular}{|c|c|c|c|c|c|}
\hline Characteristics & $\begin{array}{l}\text { Live } \\
(n=30)\end{array}$ & $\begin{array}{l}\text { Death } \\
(n=26)\end{array}$ & $\begin{array}{l}\text { Survival time (month) } \\
\text { median (CI 95\%) }\end{array}$ & $\begin{array}{l}\text { Overall } \\
\text { survival } \\
(\%)\end{array}$ & $\mathbf{p}$ \\
\hline \multicolumn{6}{|l|}{ Age (years) } \\
\hline$<60$ & $15(47)$ & $17(53)$ & $25.1(20.7-29.5)$ & 45 & \multirow[t]{3}{*}{ NS } \\
\hline$\geq 60$ & $15(63)$ & $9(38)$ & $27.6(22.6-32.5)$ & 62.5 & \\
\hline \multicolumn{5}{|c|}{ Body M ass Index $\left(\mathrm{kg} / \mathrm{m}^{2}\right)$} & \\
\hline$<30$ & $23(56)$ & $18(44)$ & $26.1(22.2-30.1)$ & 56.1 & \multirow[t]{2}{*}{ NS } \\
\hline$>30$ & $7(47)$ & $8(53)$ & $26.3(20.2-32.3)$ & 46.7 & \\
\hline \multicolumn{6}{|l|}{ Parity } \\
\hline Nulliparous & $9(53)$ & $8(47)$ & $24.8(17.9-31.6)$ & 52.9 & \multirow[t]{2}{*}{ NS } \\
\hline Multiparous & $21(54)$ & $18(46)$ & $26.8(23.1-30.6)$ & 53.8 & \\
\hline \multicolumn{6}{|l|}{ M enopause } \\
\hline Yes & $23(52)$ & $21(48)$ & $26.2(22.4-30.1)$ & 52.3 & \multirow[t]{2}{*}{ NS } \\
\hline No & $7(58)$ & $5(42)$ & $26.1(19.3-32.7)$ & 58.3 & \\
\hline \multicolumn{6}{|l|}{ LVSI } \\
\hline Positive & $9(50)$ & $9(50)$ & $26.5(20.5-32.5)$ & 50 & \multirow[t]{3}{*}{ NS } \\
\hline N egative & $21(55)$ & $17(45)$ & $26(22.1-30)$ & 55.3 & \\
\hline Stadium & & & & & \\
\hline
\end{tabular}




\begin{tabular}{llllll}
\hline IB grade III & $8(62)$ & $5(38)$ & $29.1(23.4-34.6)$ & 61.5 & NS \\
II & $6(55)$ & $5(45)$ & $23.9(16.1-31.7)$ & 54.5 & \\
III & $16(50)$ & $16(50)$ & $25.8(21.3-30.4)$ & 50 & \\
Recurrence & & & & & \\
Positive & $4(36)$ & $7(64)$ & $24.6(22.9-29.5)$ & 36.4 & NS \\
N egative & $26(58)$ & $19(42)$ & $26.6(22.8-30.4)$ & 57.8 & \\
\hline
\end{tabular}

*NS: N ot Significant

Table 3: Disease Free Survival-3 years

\begin{tabular}{|c|c|c|c|c|}
\hline \multirow[t]{2}{*}{ Characteristics } & \multicolumn{2}{|c|}{ Recurrence } & \multirow{2}{*}{$\begin{array}{l}\text { DFS-3 years (\%) } \\
\text { (log rank test) }\end{array}$} & \multirow[t]{2}{*}{$\mathbf{p}$} \\
\hline & Yes & No & & \\
\hline \multicolumn{5}{|l|}{ A ge (years) } \\
\hline$<60$ & $3(18)$ & $14(82)$ & 82.4 & \multirow[t]{2}{*}{ NS } \\
\hline$\geq 60$ & $2(13)$ & $13(87)$ & 86.7 & \\
\hline \multicolumn{4}{|l|}{$\bar{B}$ Body $M$ ass Index $\left(\mathrm{kg} / \mathrm{m}^{2}\right)$} & \multirow[t]{3}{*}{ NS } \\
\hline$<30$ & $5(20)$ & $20(80)$ & 80 & \\
\hline$>30$ & $0(0)$ & $7(100)$ & 100 & \\
\hline \multicolumn{5}{|l|}{ Parity } \\
\hline Nulliparous & $1(11)$ & $8(89)$ & 88.9 & \multirow[t]{2}{*}{ NS } \\
\hline Multiparous & $4(17)$ & $19(83)$ & 82.6 & \\
\hline \multicolumn{5}{|l|}{ M enopause } \\
\hline Yes & $4(15)$ & $23(85)$ & 85.2 & \multirow[t]{2}{*}{ NS } \\
\hline No & $1(20)$ & $4(80)$ & 80 & \\
\hline \multicolumn{5}{|l|}{ LVSI } \\
\hline Positive & $2(18)$ & $9(82)$ & 81.8 & \multirow[t]{3}{*}{ NS } \\
\hline N egative & $3(14)$ & $18(86)$ & 85.7 & \\
\hline \multicolumn{4}{|l|}{ Stadium } & \\
\hline IB grade III & $1(13)$ & $7(88)$ & 87.5 & \multirow[t]{3}{*}{ NS } \\
\hline 11 & $2(29)$ & $5(71)$ & 71.4 & \\
\hline III & $2(12)$ & $15(88)$ & 88.2 & \\
\hline
\end{tabular}

*N S: N ot Significant

Table 4: Risk factors based on LVSI

\begin{tabular}{llll}
\hline Characteristics & $\begin{array}{l}\text { LVSI (+) } \\
\text { (n=18) }\end{array}$ & $\begin{array}{l}\text { LVSI (-) } \\
\text { (n=38) }\end{array}$ & p \\
\hline $\begin{array}{l}\text { Age (years) } \\
<60\end{array}$ & $12(38)$ & $20(63)$ & NS \\
$\begin{array}{l}\text { Body Mass } \\
\text { Bodndex }\end{array}$ & $6(25)$ & $18(75)$ & \\
$\begin{array}{l}\text { kg/m²) } \\
<30\end{array}$ & $14(34)$ & $27(66)$ & NS \\
$>30$ & $4(27)$ & $11(73)$ & \\
$\begin{array}{l}\text { Parity } \\
\text { Nulliparous }\end{array}$ & $8(47)$ & $9(53)$ & NS \\
M ultiparous & $10(26)$ & $29(74)$ & \\
M enopause & & & \\
Yes & $14(32)$ & $30(68)$ & NS \\
N o & $4(33)$ & $8(67)$ & \\
Stadium & & & \\
IB grade III & $2(15)$ & $11(85)$ & 0.01 \\
II & $1(8)$ & $11(92)$ & \\
III & $15(48)$ & $16(52)$ & \\
Recurrence & & & \\
Positive & $5(45)$ & $6(55)$ & NS \\
Negative & $13(29)$ & $32(71)$ & \\
\hline
\end{tabular}

*NS: N ot Significant

\section{DISCUSSION}

LVSI acts as prognostic factor for high-risk endometrioid type endometrial cancer associated with stage endometrial cancer. The higher the stage, the LVSI will most likely be found. The most important factors for endometrial cancer prognosis according to FIGO are staging, myometrial invasion, histological type, and degree of differentiation. Based on stages according to FIGO, the 5-year survival rate for stage I disease is $87 \%$, stage II is $76 \%$, and stage III is $59 \%$ (12).

In this study, the age of $>60$ years was mostly found in the patients. In the U nited States, obtained data showed that the average age of endometrial cancer patients was 62 years. The distribution of age from 2005 to 2009 in the U nited States at the age of $55-64$ years reached $34.5 \%$ from all cases of endometrial cancer. As for the age group 45-55 years, it reached $17.2 \%$ (1). The age category showed that age $>60$ years had a better DFS compared to $<60$ years of age, which was $86.7 \%$ compared to $82.4 \%$. There was no difference between age and DFS for 3 years in this study. This is consistent with theprevious study which found no significant relationship for the influence of age on the incidence of recurrence in grade 3 endometrial cancer (13).

Population of endometrioid type of high risk endometrial cancer with BM I $<30 \mathrm{~kg} / \mathrm{m}^{2}$ is in accordance with data from Sanglah General Hospital, Indonesia regarding population from August 2012 to July 2014, which also received 
distribution of endometrial cancer based on body mass index between $18.5-22.9 \mathrm{~kg} / \mathrm{m}^{2}$. This might be because the average Indonesian woman is still in the category of normal body mass index, only a small proportion are obese (14). In this study, a better DFS was found in patients with a BMI> 30 $\mathrm{kg} / \mathrm{m}^{2}$, but it was not statistically significant because in patients with $\mathrm{BMI}>30 \mathrm{~kg} / \mathrm{m}^{2}$, no one experienced a recurrence, but some non-obese patients experienced a recurrence. This is in contrast with previous study examining adjuvant and $\mathrm{OS}$ therapy in obese endometrial cancer patients. Out of 378 post-surgical staging women, the recurrence rate was 3\% (76\% BMI $<30$ vs $79 \% \mathrm{BMI}>30, \mathrm{p}=$ $0.64)$. O besity is associated with an increased incidence of endometrial cancer due to estrogen stimulation of endometrium resulting from adipocyte conversion, namely androstenedione to estrone (15).

The nulliparous group had a worse median survival time compared to the multipara group. This is consistent with the study in which women with nulliparous had a 5-year survival rate that was worse than women who had given birth 1 or more times ( $57 \%$ vs $81 \%, p=0.0001$ ) (16). However, no statistically significant results were obtained in this study.

The majority of patients had experienced menopause but found no statistically significant differences regarding menopause and OS were found. M enarcheat an early age and late menopause are risk factors for endometrial cancer, both due to prolonged exposure to estrogen. About $70 \%$ of all women diagnosed with endometrial cancer are postmenopausal (17). M enopausal patients who experience recurrence are higher than those who have not yet menopausal. This is line with earlier study which reported 12 patients experiencing recurrence of 72 postmenopausal and 4 patients experiencing recurrence of 45 premenopausal patients (13). Theseresults are similar to another study which shows that menopausal status is not significant as a prognostic factor for endometrial cancer (18).

In this study, there were no significant differences regarding LVSI and DFS 3 years. This results are not in line with other studies which showed a significant relationship between LVSI and recurrence $(13,19,20)$. This study found 2 patients (18\%) with positive LVSI experienced a recurrence, and 3 patients (14\%) with negative LVSI experienced a relapse, but no significant effect was found. This is not in accordancewith another study showing recurrence rate of $14.2 \%$ in patients with positive LVSI and $3.8 \%$ of patients with negative LVSI (21).

In this study, it was found that patients who had a recurrence had worse OS compared to patients who did not experience recurrence. The survival time rate of patients who experienced a recurrence was worse compared to patients who did not experience a recurrence, but it was not significant. In this study, OS stage III IB group had a better OS compared to stage III.

\section{CONCLUSION}

OS and DFS-3 years in patients with prognostic factors positive LVSI are lower than those with negative LVSI. The presence of LVSI have no significant effect with DFS and OS in high-risk endometrioid-type endometrial cancer patients. LVSI acts as prognostic factor for high-risk endometrioid type endometrial cancer associated with stage endometrial cancer.

\section{REFERENCES}

1. Chen L, Dizon DS. Endometrial carcinoma: Epidemiology, risk factors, and prevention.

2. Geels YP, Pijnenborg JMA, Gordon BBM, Fogel $M$, Altevogt $P, M$ asadah $R$, et al. LICAM Expression is Related to Non-Endometrioid Histology, and Prognostic for Poor Outcome in Endometrioid Endometrial Carcinoma. Pathol Oncol Res. 2016;22(4):863-8.

3. Torre LA, Bray F, Siegel RL, Ferlay J. Global Cancer Statistics, 2012. Ca Cancer J Clin. 2015;65(2):87-108.

4. Winarto $H$, Kesty $C$, Fransisca RO, Munawaroh A, Nuranna L. Characteristics of endometrial cancer patients: A retrospective study on patients at Dr. Cipto Mangunkusumo Hospital period January 2014December 2015. Adv Sci Lett. 2017;23(7):6714-6.

5. M ingels M JJM , M asadah R, Geels Y P, Otte-H öller I, De Kievit IM, Van Der Laak JAW M , et al. High prevalence of atypical hyperplasia in the endometrium of patients with epithelial ovarian cancer. Am J Clin Pathol. 2014;142(2):213-21.

6. Lubis HP, Aldiansyah D, Siregar HS, Rivany R, H ariadi TS. Expression of natural killer cell activity with CD107a on ectopic endometrium in woman with endometriosis compared with non-endometriosis. In: IOP Conference Series Earth and Environmental Science. 2018.

7. Adenin I, Lutan D, Tandjung T, Suheimi HK, Siregar M FG. Serum prokineticin-1 (endocrine gland vascular endothelial growth factor) as an alternative marker for assessing endometrium receptivity. G Ital di Ostet e Ginecol. 2018;40(4):158-64.

8. Creutzberg $C L, N$ out RA. The role of radiotherapy in endometrial cancer: current evidence and trends. Curr Oncol Rep. 2011 Dec;13(6):472-8.

9. Rahestyningtyas $E$, Mulawardhana $P$, Lesmana $T$. Abdominal skin metastasis in endometrial cancer. $M$ aj Obstet Dan Ginekol. 2019;27(2):82-9.

10. Catherine C, Camellia V, Husada MS, Loebis B, Effendy $E$, Amin MM. Affective psychopathology towards the quality of life of breast cancer patients with radiotherapy in medan, Indonesia. O pen A ccess M aced J M ed Sci. 2019;7(9):1456-60.

11. Bosse $T$, Peters EEM, Creutzberg $C L$, JürgenliemkSchulz IM, Jobsen JJ, M ens JWM , et al. Substantial lymph-vascular space invasion (LVSI) is a significant risk factor for recurrence in endometrial cancer-a pooled analysis of PORTEC 1 and 2 trials. Eur J Cancer. 2015;51(13):1742-50.

12. Lurain JR. Uterine Cancer. In: Berek JS, editor. Berek's \& Novak's Gynecology. Philadelphia: Lippincott Williams and Wilkins; 2007.

13. Wang J, Jia N, Li Q, W ang C, Tao X, Hua K, et al. Analysis of recurrence and survival rates in grade 3 endometrioid endometrial carcinoma. Oncol Lett. 2016;12(4):2860-7.

14. Dewi PPP, Budiana ING. Profil Pasien Kanker 
Endometrium Di RSUP Sanglah Denpasar Periode Agustus 2012-Juli 2014. E-Jurnal Med Udayana. 2017;6(8).

15. Martra F, Kunos C, Gibbons H, Zola P, Galletto L, DeBernardo $R$, et al. Adjuvant treatment and survival in obese women with endometrial cancer: an international collaborativestudy. A m J Obstet Gynecol. 2008;198(1):89-el.

16. Salvesen HB, Akslen LA, Albrektsen G, Iversen OE. Poorer survival of nulliparous women with endometrial carcinoma. Cancer [Internet]. $1998 \mathrm{Apr}$ 1;82(7):1328-33. Available from: https://doi.org/10.1002/(SICI)10970142(19980401)82:7\%3C 1328::AIDCNCR16\%3E3.0.CO

17. Lindemann $K, V$ atten $L$ J, Ellstrøm-Engh $M$, Eskild $A$. Body mass, diabetes and smoking, and endometrial cancer risk: a follow-up study. $\mathrm{Br} J$ Cancer. 2008;98(9):1582-5.

18. Bajracharya SR, Juan FY. Prognostic factors in endometrial cancer. J Inst M ed. 2013;35(1):9-17.

19. Salvesen HB, Akslen LA, Albrektsen G, I versen OE. Poorer survival of nulliparous women with endometrial carcinoma. Cancer. 1998 Apr 1;82(7):1328-33.

20. M oradokkasem W, Saeaib N, Liabsuetrakul T. Disease Free Survival of Stage I Endometrial Cancer after Surgery with or without Adjuvant Treatment. Folia M edica Indones. 2019;55(1):37-42.

21. dos Reis R, Burzawa JK, Tsunoda AT, Hosaka M, Frumovitz M, W estin SN, et al. Lymphovascular Space Invasion Portends Poor Prognosis in Low-Risk Endometrial Cancer. Int J Gynecol Cancer. 2015 Sep;25(7):1292-9. 